\title{
The Biologically-Based Bias of Personality Disorder Diagnosis
}

\author{
Steven Hertler * \\ Department of Psychology, College of New Rochelle, New Rochelle, NY, USA
}

Keywords: life history, personality, diagnosis, disorder, DSM, evolution

\section{INTRODUCTION}

More than previous versions, the American Psychiatric Association's (2013) fifth edition of the Diagnostic and Statistical Manual of Mental Disorders (DSM-V) formally specified the nature of a personality disorder. Going beyond specific personality disorders and their respective criteria sets, are the General Criteria for Personality Disorder (GCPD) provided in section III on page 761 of DSM-V. Much of this list simply specifies that impairments must be enduring-transcending time, place, medical status, and developmental period. It is only the first two, criterion $A$ and criterion $B$, which positively define a personality disorder. Specifically, criterion $A$ states that there must be "moderate or greater impairment in personality functioning," and criterion $B$ states that there must be "one or more pathological personality traits." Thereafter, on page 762, the DSM attempts to define and operationalize the concepts of pathological personality traits and impaired personality functioning. First, DSM-V operationalizes pathological personality traits in so far as five are listed: (1) negative affectivity, (2) detachment, (3) antagonism, (4) disinhibition, and (5) psychoticism. Second, in describing personality functioning, there is mention of disturbances in self and interpersonal functioning, which are taken to "constitute the core of personality psychopathology." DSM-V proceeds to parse self and interpersonal functioning further: "Selffunctioning involves identity and self-direction; interpersonal functioning involves empathy and intimacy."

All such efforts are commendable improvements on what would otherwise have been imprecise concepts liable to hold different meanings for different readers. Precision is gained by exposition. Yet, precision invites criticism. With implicit assumptions giving way to explicit assertions, as collected across various tables, terms, and operational definitions within the GCPD, personality disorder diagnosis can be recognized as relativistic. When clinical judgment, diagnostic tradition and psychiatric authority are exchanged for empirical research, one finds personality variables like those embodied in the GCPD unassociated with deficits in vocation, mating success, finance, and health (Ullrich et al., 2007; Gutiérrez et al., 2013; Vall et al., 2015). At any point along the continuum of personality, instead of unalloyed deficits and beneficial traits, humans experience fitness relevant trade-offs (Nettle, 2006; Brumbach et al., 2009), as do damselflies (Rodin and Johansson, 2004), rainbow trout (Schjolden et al., 2006), house mice (Rauw, 2006) and a host of other animals displaying rudimentary personalities (Bell, 2007; Wolf et al., 2007; Biro and Stamps, 2008; Dammhahn, 2012; Favreau et al., 2014). What is true for traits may be true for personalities. As previously reviewed (Hertler, 2015a), psychopathy and obsessive compulsive personality disorder have both been described as strategic, evolved patterns, rather than dysfunctional personality disorders. Moreover, a recent study found personality extremes consistent with DSM-V disorders to be sexually selected via female choice (Vall et al., 2015). With the fact of relativism being elsewhere treated (Hertler, 2015b), it suffices to state that the GCPD rests on clinical assumptions of pathology which do not appear to equate to impairments in evolutionarily relevant life outcomes. Herein, it is not the question of relativism itself that is pursued, but the nature of that relativism. GCPD criteria are neither arbitrarily relativistic nor culturally relativistic; instead they show a particular bias, comprehensible only from a life history evolutionary vantage point. 


\section{Bringing a Life History Evolutionary Perspective to Bear}

Life history evolution is a coherent sub-discipline of evolutionary biology that originated with the study of variation across seven developmental trait clusters, among which were lifespan, maturation rate, and brood size. Life histories are distributed across a gradient from fast or $r$-selected, to slow or $\mathrm{K}$ selected. Most basically, and confined to the classic biomarkers upon which life history theory was grounded, fast and slow relate to the pace of development. Fast or $r$-selected species mature quickly, breed much, and die young, whereas slow or $K$-selected species show the opposite pattern, living long enough to support extensive prenatal growth and thereafter lavish resources on a small number of long-lived young. Contrast the elephant with the rabbit. In number, size, and care of young, as in longevity, growth and maturation rate, these animals are extraordinarily dissimilar. Life history variation, though greatest between species, is present within species; including the human species. Within the past three decades, life history evolution has been particularly successful in logically grouping altruism and affiliation, risk aversion and inhibition, as well as future oriented thought and delay of gratification (Figueredo et al., 2006; Jonason and Tost, 2010; McDonald et al., 2012; Hertler, 2015a), showing them to be $K$-selected. Opposite these, across a continuum, are $r$-selected antagonism, sensation seeking, disinhibition, and an orientation to the present. The original biological, as well as the aforementioned psychological and social life history variables, are collectively calibrated by mortality; specifically the rate, predictability and controllability of mortality. In $K$-selected regimes, mortality is rare, predictable and controllable; in $r$-selected regimes, mortality is common, unpredictable, and uncontrollable (Schechter and Francis, 2010). As investing in a few, slow growing, late maturing young is impractical and maladaptive under an $r$ selected regime with high, and highly unpredictable mortality, so is excessive altruism, risk-aversion or future orientation. There is not sufficient time or safety to capitalize on investment. So, life history creates a sort of time relevant biology organized around mortality.

\section{The General Criteria for Personality Disorder as an Inventory of Fast Life History Markers}

When the GCPD is viewed from a life history perspective, it becomes apparent that the $r$-selected tail of the life history distribution is being wontedly pathologized. The lion's share of GCPD components are indeed fast life history traits. GCPD is first broadly conceived of as self-impairment, which relates to limited self-direction and goal-pursuit, both of which mark the present oriented opportunism of the $r$-strategist (Figueredo and Rushton, 2009). Under self-impairment also come the personality traits of psychoticism and disinhibition. Within psychoticism, as conceived by Eysenck, are the traits of impulsivity, sensationseeking and risk-taking, all of which are $r$-selected. The selfimpairment component of the GCPD marks as pathological, a present focused time orientation and the behaviors that follow from such an orientation. The $r$-selected are persons on the tail end of a distribution adapted best to novel, changing and unpredictable conditions. Impulsivity, sensation seeking, disinhibition, risk-taking and presentism, rather than being indicative of pathological self-impairment as per the GCPD, are behavioral dispositions that follow logically, and function suitably, in the context of unsafe and unpredictable environments (Griskevicius et al., 2011).

The General Criteria for Personality Disorder (GCPD) is secondly broadly conceived of as interpersonal-impairment, which relates to deficits in empathetic response, durable intimate connections, and mutual interpersonal regard, all of which mark the instrumental selfishness of the $r$-strategist (Olderbak and Figueredo, 2010). Under interpersonal-impairment also come the personality traits of negative affectivity, detachment and antagonism. Within a life history framework, however, negative affectivity, detachment and antagonism are simply manifestations of a fast life history which expresses "less mutualistic and more antagonistic" behavior in response to "unstable, unpredictable, and uncontrollable" conditions (Sherman et al., 2013). In contrast to $r$-strategists, $K$-strategists, "prefer long-term and cooperative social as well as sexual relationships, which are easier and more profitable to maintain in their characteristically more stable, predictable, and controllable environments" (Figueredo and Rushton, 2009). Which is expressed relates not at all to questions of superiority or inferiority, or more pertinently, ordered or disordered personality. Instrumental or exploitative exchanges, restricted empathy and altruism, and short-term mating, with its emphasis of quantity above quality of offspring, rather than being indicative of pathological interpersonal-impairment as per the GCPD, are interpersonal strategies that compete effectively with their opposite, most especially in unsafe and unpredictable environments (Brumbach et al., 2009).

\section{THE GCPD'S CORRESPONDENCE WITH LIFE HISTORY MEASURES AND FACTORS}

Life history measures and factors run parallel to the GCPD. The Life Experiences Questionnaire, the Self-Control Schedule, The Barrett Impulsivity Scale, the Mating Effort Scale and the Mate Value Inventory all informed the construction of explicit life history measures like the Arizona Life History Battery (Figueredo et al., 2004, 2006; Gladden et al., 2009). Not only do life history batteries overlap significantly with the GCPD, so do aggregated life history variables like the K-Factor, Covitality, General Factor of Personality (GFP), and the Super-K Factor. The K-Factor, for instance, predicts attachment, mating effort, Machiavellianism, and risk-propensity (Figueredo et al., 2005). Further still, nearly uniformly related to the GCPD, depressions in the following factors were found to be inter-correlated, heritable markers of $r$-selected life histories: (1) quality relationships with mother, father, spouse, children; (2) family support; (3) altruism toward kin; (4) friends support; (5) altruism toward non-kin; (6) close relationship quality; (7) communitarian beliefs; (8) 
religiosity; (9) financial status; (10) advice seeking; (11) foresight/anticipation; (12) insight into past; (13) primary control/persistence; (14) flexible/positive reappraisal; (15) selfdirectedness/planning (Figueredo et al., 2004). As will be obvious, the first eight life history correlates equate closely to the GCPD's interpersonal-impairment component, with its emphasis on affiliation and reciprocation. In turn, most of the remaining seven life history correlates relate to the GCPD's self-impairment component, with its emphasis on restraint and future oriented planning.

\section{CONCLUSIONS}

Life histories, whether $r$ or $K$ selected, are heritable and developmentally sensitive patterns across which there is intra-population variation. This variation, though moderated environmentally, is evolutionarily created and maintained (Réale et al., 2010). Again, neither end of the life history distribution is absolutely better or worse; rather each is better or worse relative to a specified mortality regime (Chisholm, 1999). In other words, as mortality waxes and wanes in randomness and rate, so will the fitness of GCPD related life history traits, such as altruism, foresight, persistence and planning. All these traits assume an extended future where what is sown can be reaped, whether it is a hard-earned reputation for cooperation, or a long-term goal achieved (Geronimus, 1987). The $K$ strategist is evolutionarily and developmentally prepared to maximize long-term benefit and altruistic cooperation in predictable and controllable environments. The $r$ strategist is evolutionarily and developmentally prepared to maximize resource extraction and immediate interpersonal gains in unpredictable and uncontrollable environments (Olderbak et al., 2014). Lamentably, the GCPD conflates strategic difference and pathological dysfunction because it was created in the absence of a life history perspective, or apparently in the absence of any evolutionary grounding.

Assuredly, there is no conscious effort to use psychiatric diagnosis of personality disorders as an agent of social control or a tool of discrimination. Nevertheless, adrift from evolutionary moorings, GCPD standards have exposed a non-arbitrary strain of relativism; they too closely resemble a compilation of perceived $r$-failings compiled by $K$-strategists. Indeed, it is not only that the $r$-strategist is likely to function as the identified patient, but that the $K$-strategist is likely to be the diagnosing clinician. Pursuing this notion, there is some evidence that clinicians more consistently live by, and evince, contemporary middle-class North American Values (Greene, 1985; Garb, 1997; Hall, 2001; Samuels, 2004), which are K-selected correlates (Figueredo et al., 2006). Similarly, relating to the longevity and bodily maintenance that marks the $K$-selected
(Kaplan et al., 2000; Flatt et al., 2013), physicians as a group elevate on health behaviors (Frank, 2004) and longevity (Frank et al., 2000), while having significantly lower all-cause mortality rates compared to the general population (Torre et al., 2005; Aasland et al., 2011). Additionally, the brain and behavioral $K$ selected correlates of intelligence (Rushton, 2004) and education (Figueredo et al., 2006) are directly relevant to patently educated and disproportionately intelligent psychiatrists and psychologists culled from the general population via admissions tests (SAT, GRE, MCAT) graduate programs, internships, residencies, as well as post-doctoral and licensure requirements. In turn, education is associated with (Stentz et al., 2016) delayed (Pew Research Center, 2016) and limited reproduction (Weeden et al., 2006), both foundational $K$-selected biomarkers (Chisholm, 1999).

Being that diagnosing clinicians may well be disproportionately $K$-selected, it then becomes important to understand that $K$ strategists don't just evince the $K$ strategy, they actively shape the environment toward the stability and predictability wherein it best operates. The $K$-selected are "overrepresented among the rule-enforcers" (Gladden et al., 2009), often serving to promulgate and reinforce social norms (Figueredo et al., 2006, 2007; Sherman et al., 2013). This is a process of niche construction wherein the environment is accommodated to the needs of the organism, not taken as it is found. $K$-selected rule creation and enforcement, like the bird building a nest, or the beaver building a dam (Hughs, 2012), is indicative of an extended phenotype (Dawkins, 1999). One end of the life history gradient working against the other is then an example of competition in which the weapons are not claws and teeth, but agents of social control like prisons and sanctions. Legislating against and locking up those that express $r$ selected extremes may be defensible within the criminal justice system. Competition of this nature, however, is not patently appropriate for the diagnostic endeavor to the extent that it has pretensions to objectively identifying instances of pathology. As race, class and sex now are, it follows that diagnostic categories and decisions should then be scrutinized for life history related bias. With respect specifically to the GCPD, it might be removed in favor of a life history informed system that eschews diagnosing r-selected pathology in favor of identifying its incongruous expression in $K$-selected contexts.

\section{AUTHOR CONTRIBUTIONS}

The author confirms being the sole contributor of this work and approved it for publication.

\section{ACKNOWLEDGMENTS}

This article is indebted to the works of A. J. Figueredo and colleagues, which were much cited. 


\section{REFERENCES}

Aasland, O. G., Hem, E., Haldorsen, T., and Ekeberg, Ø. (2011). Mortality among Norwegian doctors 1960-2000. BMC Public Health 11:173. doi: 10.1186/14712458-11-173

American Psychiatric Association (2013). Diagnostic and Statistical Manual of Mental Disorders, 5th Edn. Washington, DC: American Psychiatric Association.

Bell, A. M. (2007). Evolutionary biology: animal personalities. Nature 447, 539-540. doi: 10.1038/447539a

Biro, P. A., and Stamps, J. A. (2008). Are animal personality traits linked to life-history productivity? Trends Ecol. Evol. 23, 361-368. doi: 10.1016/j.tree.2008.04.003

Brumbach, B. H., Figueredo, A. J., and Ellis, B. J. (2009). Effects of harsh and unpredictable environments in adolescence on development of life history strategies. Hum. Nat. 20, 25-51. doi: 10.1007/s12110-009-9059-3

Chisholm, J. S. (1999). Attachment and time preference: relations between early stress and sexual behavior in a sample of American University Women. Hum. Nat. 10, 51-83. doi: 10.1007/s12110-999-1001-1

Dammhahn, M. (2012). Are personality differences in a small iteroparous mammal maintained by a life-history trade-off? Proc. R. Soc. B Biol. Sci. 279, 2645-2651. doi: $10.1098 / \mathrm{rspb} .2012 .0212$

Dawkins, R. (1999). The Extended Phenotype: The Long Reach of the Gene. New York, NY: Oxford Paperbacks.

Favreau, F. R., Goldizen, A. W., Fritz, H., Blomberg, S. P., Best, E. C., and Pays, O. (2014). Within-population differences in personality and plasticity in the tradeoff between vigilance and foraging in kangaroos. Anim. Behav. 92, 175-184. doi: 10.1016/j.anbehav.2014.04.003

Figueredo, A. J., and Rushton, J. P. (2009). Evidence for shared genetic dominance between the general factor of personality, mental and physical health, and life history traits. Twin Res. Hum. Genet. 12, 555-563. doi: 10.1375/twin.12.6.555

Figueredo, A. J., Vasquez, G., Brumbach, B. H., and Schneider, S. M. (2004). The heritability of life history strategy: the $K$-factor, covitality, and personality. Soc. Biol. 51, 121-143. doi: 10.1080/19485565.2004.9989090

Figueredo, A. J., Vásquez, G., Brumbach, B. H., and Schneider, S. M. (2007). The K-factor, Covitality, and personality. Hum. Nat. 18, 47-73. doi: 10.1007/BF02820846

Figueredo, A. J., Vásquez, G., Brumbach, B. H., Schneider, S. M. R., Sefcek, J. A., Tal, I. R., et al. (2006). Consilience and life history theory: from genes to brain to reproductive strategy. Dev. Rev. 26, 243-275. doi: 10.1016/j.dr.2006.02.002

Figueredo, A. J., Vásquez, G., Brumbach, B. H., Sefcek, J. A., Kirsner, B. R., and Jacobs, W. J. (2005). The K-factor: individual differences in life history strategy. Pers. Individ. Dif. 39, 1349-1360. doi: 10.1016/j.paid.2005.06.009

Flatt, T., Amdam, G. V., Kirkwood, T. B., and Omholt, S. W. (2013). Life-history evolution and the polyphenic regulation of somatic maintenance and survival. Q. Rev. Biol. 88, 185-218. doi: 10.1086/671484

Frank, E. (2004). Physician health and patient care. JAMA 291, 637-637. doi: 10.1001/jama.291.5.637

Frank, E., Biola, H., and Burnett, C. A. (2000). Mortality rates and causes among US physicians. Am. J. Prev. Med. 19, 155-159. doi: 10.1016/S0749-3797(00)00201-4

Garb, H. N. (1997). Race bias, social class bias, and gender bias in clinical judgment. Clin. Psychol. 4, 99-120. doi: 10.1111/j.1468-2850.1997.tb00104.x

Geronimus, A. T. (1987). On teenage childbearing and neonatal mortality in the United States. Popul. Dev. Rev. 245-279. doi: 10.2307/1973193

Gladden, P. R., Figueredo, A. J., and Jacobs, W. J. (2009). Life history strategy, psychopathic attitudes, personality, and general intelligence. Pers. Individ. Dif. 46, 270-275. doi: 10.1016/j.paid.2008.10.010

Greene, B. A. (1985). Considerations in the treatment of Black patients by White therapists. Psychotherapy 22, 389. doi: 10.1037/h0085519

Griskevicius, V., Delton, A. W., Robertson, T. E., and Tybur, J. M. (2011). Environmental contingency in life history strategies: the influence of mortality and socioeconomic status on reproductive timing. J. Pers. Soc. Psychol. 100, 241. doi: $10.1037 / \mathrm{a} 0021082$

Gutiérrez, F., Gárriz, M., Peri, J. M., Ferraz, L., Sol, D., Navarro, J. B., et al. (2013). Fitness costs and benefits of personality disorder traits. Evol. Hum. Behav. 34, 41-48. doi: 10.1016/j.evolhumbehav.2012.09.001

Hall, G. C. N. (2001). Psychotherapy research with ethnic minorities: empirical, ethical, and conceptual issues. J. Consult. Clin. Psychol. 69:502. doi: 10.1037/0022-006X.69.3.502
Hertler, S. C. (2015a). The biology of obsessive-compulsive personality disorder symptomatology: identifying an extremely K-selected life history variant. Evol. Psychol. Sci. 2, 1-15. doi: 10.1007/s40806-015-0030-8

Hertler, S. C. (2015b). Crossing the paradigmatic divide in personality: coming to an evolutionary understanding of personality variation. J. Philos. Psychiatry. Available online at: http://www.jfpp.org/116.html?\&no_cache=1\&sword_list $\% 5 \mathrm{~B} \% 5 \mathrm{D}=$ hertler

Hughs, D. P. (2012). "Parasites and the superorganism," in Host Manipulation by Parasites, eds D. P. Hughes, J. Brodeur, and F. Thomas (New York, NY: Oxford University Press), 140-154.

Jonason, P. K., and Tost, J. (2010). I just cannot control myself: the dark triad and self-control. Pers. Individ. Dif. 49, 611-615. doi: 10.1016/j.paid.2010.05.031

Kaplan, H., Hill, K., Lancaster, J., and Hurtado, A. M. (2000). A theory of human life history evolution: diet, intelligence, and longevity. Evol. Anthropol. Iss. News Rev. 9, 156-185. doi: 10.1002/1520-6505(2000)9:4<156::AIDEVAN5>3.0.CO;2-7

McDonald, M. M., Donnellan, M. B., and Navarrete, C. D. (2012). A life history approach to understanding the dark triad. Pers. Individ. Dif. 52, 601-605. doi: 10.1016/j.paid.2011.12.003

Nettle, D. (2006). The evolution of personality variation in humans and other animals. Am. Psychol. 61:622. doi: 10.1037/0003-066X.61.6.622

Olderbak, S. G., and Figueredo, A. J. (2010). Life history strategy as a longitudinal predictor of relationship satisfaction and dissolution. Pers. Individ. Dif. 49, 234-239. doi: 10.1016/j.paid.2010.03.041

Olderbak, S., Gladden, P., Wolf, P. S. A., and Figueredo, A. J. (2014). Comparison of life history strategy measures. Pers. Individ. Dif. 58, 82-88. doi: 10.1016/j.paid.2013.10.012

Rauw, W. M. (2006). A note on behavioural response to a novel arena in lactating mice highly selected for litter size. Appl. Anim. Behav. Sci. 99, 357-365. doi: 10.1016/j.applanim.2005.10.015

Réale, D., Garant, D., Humphries, M. M., Bergeron, P., Careau, V., and Montiglio, P. O. (2010). Personality and the emergence of the pace-of-life syndrome concept at the population level. Philos. Trans. R. Soc. B Biol. Sci. 365, 4051-4063. doi: 10.1098/rstb.2010.0208

Pew Research Center (2016). For Most Highly Educated Women, Motherhood doesn't Start Until the 30s. Available online at: http://www.pewresearch. org/fact-tank/2015/01/15/for-most-highly-educated-women-motherhooddoesnt-start-until-the-30s/

Rodin, T., and Johansson, F. (2004). Conflicting selection pressures on the growth/predation-risk trade-off in a damselfly. Ecology 85, 2927-2932. doi: $10.1890 / 03-3120$

Rushton, J. P. (2004). Placing intelligence into an evolutionary framework or how $\mathrm{g}$ fits into the $\mathrm{r}-\mathrm{K}$ matrix of life-history traits including longevity. Intelligence 32, 321-328. doi: 10.1016/j.intell.2004.06.003

Samuels, A. (2004). Politics on the couch? Psychotherapy and society-Some possibilities and some limitations. Psychoanal. Dial. 14, 817-834. doi: 10.1080/10481881409348809

Schechter, D. E., and Francis, C. M. (2010). A life history approach to understanding youth time preference: mechanisms of environmental risk and uncertainty and attitudes toward risk behavior and education. Hum. Nat. 21, 140-164. doi: 10.1007/s12110-010-9084-2

Schjolden, J., Pulman, K. G. T., Pottinger, T. G., Metcalfe, N. B., and Winberg, S. (2006). Divergence in locomotor activity between two strains of rainbow trout Oncorhynchus mykiss with contrasting stress responsiveness. J. Fish Biol. 68, 920-924. doi: 10.1111/j.0022-1112.2006.00935.x

Sherman, R. A., Figueredo, A. J., and Funder, D. C. (2013). The behavioral correlates of overall and distinctive life history strategy. J. Pers. Soc. Psychol. 105, 873-888. doi: 10.1037/a0033772

Stentz, N. C., Griffith, K. A., Perkins, E., DeCastro Jones, R., and Jagsi, R. (2016). Fertility and childbearing among American Female Physicians. J. Womens Health. doi: 10.1089/jwh.2015.5638. [Epub ahead of print].

Torre, D. M., Wang, N. Y., Meoni, L. A., Young, J. H., Klag, M. J., and Ford, D. E. (2005). Suicide compared to other causes of mortality in physicians. Suic. Life Threat. Behav. 35, 146-153. doi: 10.1521/suli.35.2.146. 62878

Ullrich, S., Farrington, D. P., and Coid, J. W. (2007). Dimensions of DSMIV personality disorders and life-success. J. Pers. Disord. 21, 657-663. doi: 10.1521/pedi.2007.21.6.657 
Vall, G., Gutiérrez, F., Peri, J. M., Gárriz, M., Baillés, E., Garrido, J. M., et al. (2015). Seven dimensions of personality pathology are under sexual selection in modern Spain. Evol. Hum. Behav. 37, 169-178. doi: 10.1016/j.evolhumbehav.2015.10.004

Weeden, J., Abrams, M. J., Green, M. C., and Sabini, J. (2006). Do high-status people really have fewer children? Hum. Nat. 17, 377-392. doi: 10.1007/s12110006-1001-3

Wolf, M., Van Doorn, G. S., Leimar, O., and Weissing, F. J. (2007). Life-history trade-offs favour the evolution of animal personalities. Nature 447, 581-584. doi: $10.1038 /$ nature 05835
Conflict of Interest Statement: The author declares that the research was conducted in the absence of any commercial or financial relationships that could be construed as a potential conflict of interest.

Copyright $(0) 2016$ Hertler. This is an open-access article distributed under the terms of the Creative Commons Attribution License (CC BY). The use, distribution or reproduction in other forums is permitted, provided the original author(s) or licensor are credited and that the original publication in this journal is cited, in accordance with accepted academic practice. No use, distribution or reproduction is permitted which does not comply with these terms. 